еборейный дерматит волосистой части

головы: современные представления

об этиологии, патогенезе и терапии

Т.А. Белоусова, М.А. Горячкина, Д.Г. Катранова

ГБОУ ВПО «Первый Московский государственный медицинский университет им. И.М. Сеченова» Минздрава России

119991, Москва, ул. Трубецкая, д. 8, стр. 2

Дан обзор современных представлений об эпидемиологии, этиологии, патогенезе и принципах терапии себорейного дерматита волосистой части головы. Приводятся результаты многочисленных отечественных и зарубежных исследований, свидетельствующих о высокой клинической эфффективности шампуня 2\% кетоконазола в терапии себорейного дерматита.

Ключевые слова: себорейный дерматит волосистой части головы, дрожжеподобные грибы рода Malassezia, шампунь $2 \%$ кетоконазола.

Контактная информация: belka-1147@mail.ru. Вестник дерматологии и венерологии 2013; (6): 132_138.

\title{
Seborrheic scalp dermatitis: current concepts of its etiology, pathogenesis and therapy
}

T.A. Belousova, M.V. Goryachkina, D.G. Katranova

I.M. Sechenov First Moscow State Medical University

Trubetskaya str., 8, bldg 2, Moscow, 119991, Russia

The authors provide a review of current concepts of the epidemiology, etiology, pathogenesis and treatment principles for seborrheic scalp dermatitis. They also describe the results of multiple national and foreign studies confirming high clinical efficacy of ketoconazole $2 \%$ shampoo in the therapy of seborrheic dermatitis.

Key words: seborrheic scalp dermatitis, yeast-like fungi of the Malassezia genus, ketoconazole $2 \%$ shampoo.

Corresponding author: belka-1147@mail.ru. Vestnik Dermatologii i Venerologii 2013; 6: 132_138. 
Перхоть и себорейный дерматит (СД) являются распространенной патологией кожи головы у человека. В настоящее время эти состояния рассматриваются как проявления одного дерматоза, имеющего различную степень выраженности. Частота встречаемости простой перхоти (сухой тип) - себорейного дерматита в популяции составляет 15-20\%. Жирный тип и воспалительный (экссудативный) тип СД представляют собой более тяжелые формы заболевания. Они встречаются у $2-5 \%$ населения в возрасте $20-$ 50 лет, пик заболеваемости приходится на период 30-40 лет. Мужчины чаще, чем женщины, подвержены этому недугу и имеют более распространенные и обширные высыпания. На долю СД приходится 10\% среди всех обращений к дерматологу. Заболевание обычно начинается в пубертатном периоде, коррелируя с увеличением в этот период выработки кожного сала. СД присуща этническая избирательность Заболевание редко встречается у афроамериканцев и является частой патологией у лиц с белой кожей. Дерматоз нередко встречается у пациентов с болезнью Паркинсона и у пациентов, получающих определенные психотропные препараты, такие как галоперидол, деканоат, литий, буспирон, хлорпромазин и аминазин. СД является одной из наиболее распространенных патологий кожи у лиц, инфицированных вирусом иммунодесиццита человека, особенно тех, у которых CD4 T-клеток менее 400 в 1 мм. Показатели распространенности этой патологии у пациентов со СПИДом и болезнью Паркинсона составляют 85-95 и 35\% соответственно [1-4].

СД можно охарактеризовать как хроническое воспалительное заболевание кожи, богатой сальными железами (лицо, волосистая часть головы, туловище), характеризующееся эритематозно-сквамозными, реже папулезно-сквамозными высыпаниями, зудом и жжением. При СД поражается кожа волосистой части головы с переходом на лоб по линии роста волос. Кожа лица преимущественно поражается в области носогубных складкок, на боковых поверхностях носа (рис. 1), заушной области, наружного слухового прохода, а также бровях и переносице. Возможным проявлением СД может являться блефарит с корками медового цвета вдоль края ресниц и скоплением роговых масс вокруг ресниц. Поражаются и другие участки кожи, имеющие волосяной покров (область грудины, межлопаточная область). Частота поражения кожи лица составляет $87,7 \%$, волосистой части головы $-70,3 \%$, туловища - 26,8\%. Наиболее частым симптомом является шелушение; чешуйки могут быть серыми и сухими или же желтоватыми и жирными. Шелушению очень часто сопутствуют зуд и покраснение кожи. При СД у некоторых пациентов может не наблюдаться избыточной выработки кожного сала [5].

СД волосистой части головы характеризуется диффузным образованием желтоватых жирных чешуек

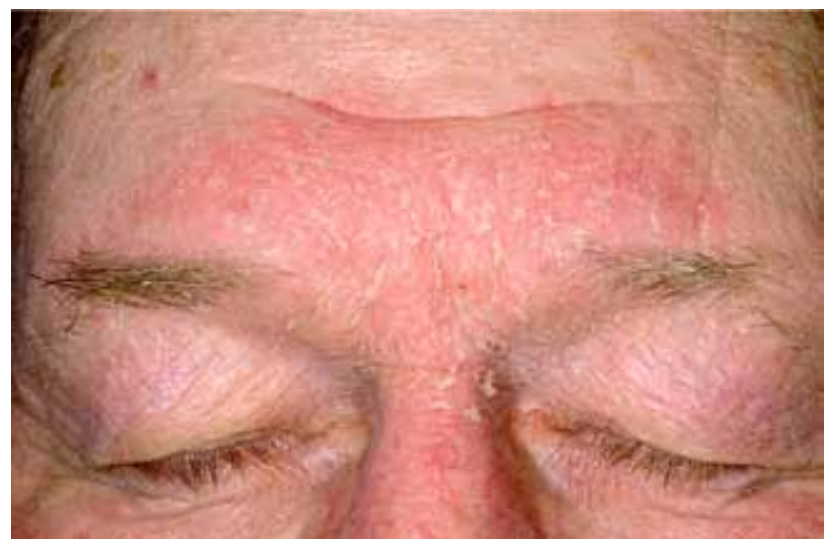

Рис. 1. Себорейный дерматит лица с крупнопластинчатой десквамацией в области лба

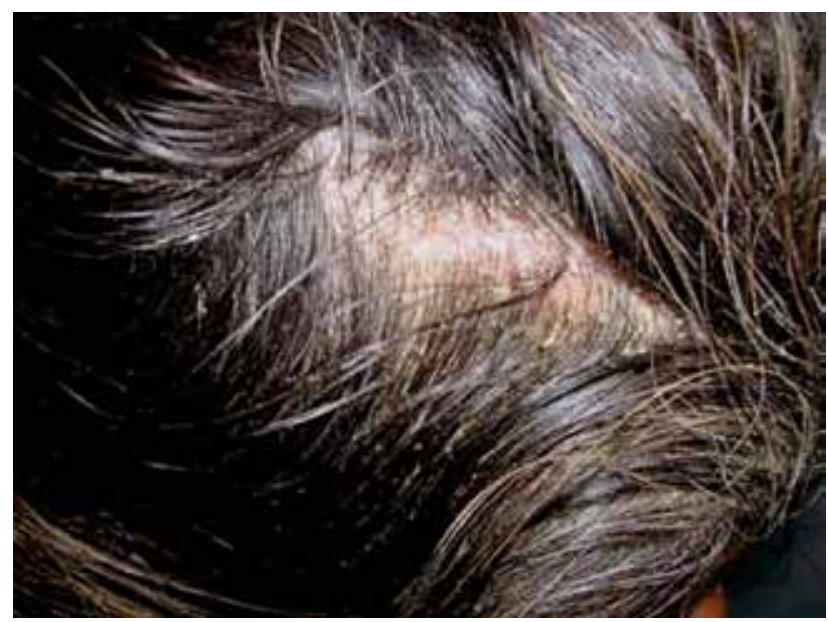

Рис Себорейный дерматит волосистой части головы. Характеризуется диффузным образованием желтоватых жирных чешуек

(рис. 2). Патологические изменения кожи головы, связанные с СД, могут оказывать неблагоприятное воздействие на состояние волосяного стержня. У лиц с СД в сравнении с нормальной популяцией волосы более тонкие, имеют более хрупкую поверхность и меньше блестят. СД также может сопровождаться повышенным выпадением волос. В зависимости от выраженности воспалительного процесса выделяют несколько типов СД волосистой части головы: сухой тип (простая перхоть) - легкая форма СД, жирный тип (восковидная перхоть), воспалительный (экссудативный) тип. Тяжелым вариантом течения СД является асбестовидный лишай. Беловато-желтые сухие чешуйки, на- 

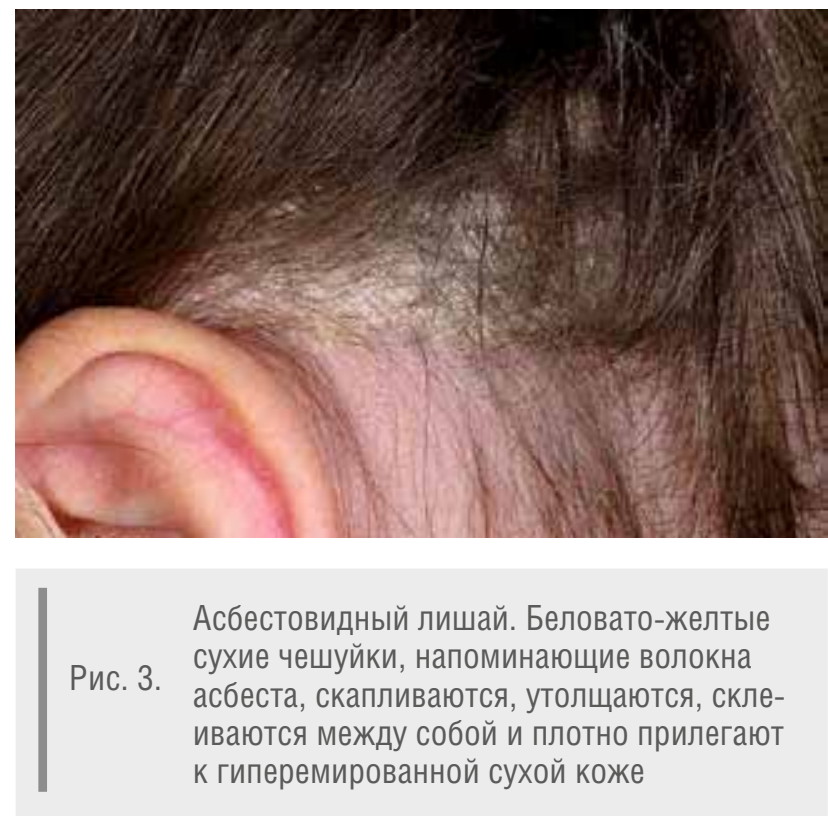

поминающие волокна асбеста, скапливаются, утолщаются, склеиваются между собой и плотно прилегают к гиперемированной сухой коже (рис. 3). Они располагаются преимущественно в теменной области, но могут занимать почти всю волосистую часть головы. Чешуйки плотно окутывают концы волос белым чехлом, склеивая их в пучки. Волосы сухие, как бы посыпаны пудрой, с течением времени могут редеть. Локализация СД на открытых участках кожи, выраженный зуд и жжение кожи вызывают у пациентов психологический дискомфорт, глубокие эмоциональные переживания и часто приводят к социальной дезадаптации, формируя психосоматичесие расстройства тревожного и депрессивного спектра [6, 7].

В настоящее время доказано, что одной из основных причин развития перхоти и СД являются дрожжеподобные грибы рода Malassezia, которые вызывают воспалительную реакцию и гиперпролиферацию эпидермиса. Впервые гипотезу о том, что причиной перхоти могут являться грибы, высказал французский микробиолог Луи Шарль Малассез около 100 лет назад, когда обнаружил дрожжеподобное вещество в чешуйках у пациента с СД. Впоследствии эта группа микроорганизмов получила имя этого исследователя.

Определенное время считалось, что дрожжевой гриб Pityrosporum ovale является причиной перхоти и СД. Дальнейшие исследования показали, что Pityrosporum ovale, Pityrosporum orbiculare и Malassezia furfur являются лишь вариантами одного и того же вида. В 1996 г. Pityrosporum был заново классифицирован в семь видов Malassezia genus. На сегодняшний день известно более 9 видов гриба Malassezia. Первоначально M. furfur признали отвечающим за об- разование перхоти и СД. В дальнейшем проведение генетических исследований позволило более точно идентифицировать характер дрожжей, обитающих на коже головы человека. В анализах с поверхности кожи головы было обнаружено преобладание двух ранее не вызывавших подозрение грибов: M. restricta и M. globosa, которые наиболее часто определялись у больных с СД и перхотью, а M. furfur был исключен из списка «подозреваемых» 6,8$]$.

В развитии СД выделяют 4 патофизиологические фазы:

1) экосистема Malassezia и взаимодействие с эпидермисом;

2) начало и развитие воспаления;

3) нарушение процессов пролиферации и дифреренциации эпидермиса;

4) нарушение строения и функциональных свойств кожного барьера.

Malassezia является условно-патогенным дрожжеподобным грибом, поражающим кожу головы, который считается этиологическим фактором, вызывающим СД. Эмпирическим фрактором, подтверждающим роль этого микроорганизма в патогенезе, является то, что лечебные вещества с противогрибковым действием активно подавляют симптомы СД и оказывают выраженное терапевтическое действие. Кроме того, эфрфективное антимикотическое лечение сопровождается уменьшением количества микроорганизмов рода Malassezia в очагах поражения по сравнению с содержанием этих грибов до лечения. Рецидив заболевания сопровождается увеличением колонизации Malassezia в зонах воспаления. Возможный этиопатологический механизм включает выделение веществ, содержащих жирные кислоты, в результате липолиза из исходных триглицеридов сального секрета, под действием липазы, которая секретируется Malassezia. Свободные жирные кислоты, особенно ненасыщенные, являются основой для образования продуктов перекисного окисления липидов, которые играют роль ключевых факторов, провоцирующих воспаление и гиперпролиферацию клеток эпидермиса, в результате чего возникают распространенные признаки и симптомы, связанные с этими заболеваниями [9].

Malassezia встречаются на поверхности эпидермиса у всех людей, но у пациентов с СД эти микроорганизмы определяются в толще рогового слоя. Эти дрожжевые клетки тесно связаны с шелушением и паракератотическими клетками. Сохранение паракератотических клеток (с неполноценными ядрами) в течение продолжительного периода в верхних отделах рогового слоя является характерным структурным признаком этих заболеваний; их количество коррелирует с выраженностью шелушения кожи. Образование паракератотических клеток, возможно, связано с гиперпролиферативными свойствами эпидермиса при СД, что подтверждается увеличением скорости обновле- 
ния и утолщением эпидермиса. Также была установлена неоднородная структура и инвагинация оболочки корнеоцитов, связанная с недостаточной синхронизацией между пролифрерацией и дифореренциацией при СД. Эти изменения вызывают нарушение влагоудерживающей способности кожи у лиц с перхотью и СД, сопровождающееся сухостью и шелушением (10).

Помимо нарушения структуры клеток при СД происходят изменения со стороны липидов эпидермиса. Характерная слоистая структура, образованная керамидами, замещается гораздо более широким неструктурированным липидным веществом. Также в цитоплазме клеток появляются липидные вкрапления неизвестного происхождения и состава. Как правило, липиды сального секрета изменяются под действием липазы, выделяемой Malassezia, образуются свободные жирные кислоты. Они, в свою очередь, являются основой для образования продуктов перекисного окисления липидов - ключевых фракторов, провоцирующих воспаление. В недавно выполненном гистологическом исследовании были установлены признаки воспаления (периваскулярные лимфоциты) и произведена подробная гистологическая систематизация воспалительных клеток. В пораженных участках кожи у больных СД была выявлена инфильтрация нейтрофилами, МHC+ лимфоидными клетками и NK клетками. Такие структурные отклонения на клеточном уровне нарушают функциональное состояния кожного барьера. Такой барьер не так эффрективно, как барьер нормальной кожи, препятствует испарению жидкости и пенетрации экзогенных веществ. Изменения строения и функции эпидермиса приводят к ускорению прогрессирования заболевания, снижению эффрективности защитных свойств кожи, препятствующих пенетрации воспалительных факторов, которые выделяются в результате метаболизма Malassezia. Благодаря недавно разработанным новым надежным и воспроизводимым методам стало возможным изучение эпидермиса на молекулярном уровне. Исследование пунктатов кожи, взятых в очагах поражения у больных с перхотью СД, с помощью иммуногистохимического анализа установило увеличение концентраций провоспалительных цито-

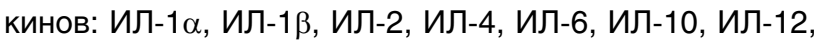
фактора некроза опухоли- $\alpha$ и интерфрерона- $\gamma$. С помощью этих же методик выявлено, что в участках непораженной кожи у лиц с СД уровень медиаторов воспаления также был выше, чем в коже у здоровых добровольцев. Эти данные являются доказательством того, что при перхоти СД существуют выраженные отличия кожи от нормы на молекулярном уровне, и служат подтверждением присутствия при этих заболеваниях воспалительного компонента [11, 12].

Изучение структурных биомаркеров, связанных с дифференциацией белка инволюкрина, фрормирующего клеточную оболочку, показало незначительные отличия от нормы, однако этот показатель был чув- ствительным к результатом лечения. У больных СД выявлено значительное снижение содержания кератина типов 1, 10 и 11, что свидетельствует о неполной терминальной дифференциации. Количественное определение эпидермальных межклеточных липидов установило снижение общего содержания керамидов и сфингооснований, что является одной из причин нарушения барьерной функции кожи. Таким образом, благодаря возможностям новых молекулярных методов исследования установлена этиологическая роль Malassezia и выделены основные патофизиологические механизмы развития СД. Колонизирующие на коже липофильные дрожжи и продукты их метаболизма инициируют запуск воспалительного каскада, который приводит к гиперпролиферации и неполной дифференцировке корнеоцитов с последующим нарушением барьера рогового слоя [12].

Терапия СД включает использование наружных средств с различным механизмом действия: противогрибковые, противовоспалительные, кератолитики и оказывающие комплексное действие. Противогрибковые средства являются основой терапии СД. Они представлены несколькими группами препаратов: антимикотиками из группы азолов (кетоконазол, климбазол, и др.), аллиламинами (тербинафин) и циклопироксоламином. В более легких случаях при простой перхоти используются дерматологические средства с противогрибковой активностью: препараты цинка (оксид цинка, сульфат цинка, пиритион цинка), дегтя, ихтиола, серы (дисульфид селена, дисульфат селена) и др. Среди противогрибковых средств препаратами первой линии выбора являются азолы. Последние помимо антималассезиозной активности обладают также противовоспалительными свойствами. Они ингибируют 5-липоксигеназу, подавляющую синтез лейкотриена В4 в коже, что делает их выбор предпочтительным. Наиболее изученным из азолов является кетоконазол. Шампунь Низорал (кетоконазол 1 и 2\%) - оригинальный препарат, синтезированный компанией Janssen Cilag в 1976 г. Это первый противогрибковый препарат широкого спектра действия, который произвел революцию в лечении микозов. Синтетическое производное имидазол-диоксолана кетоконазол обладает широким спектром противогрибкового действия в отношении многих грибов: Trichophyton spp., Epidermophyton spp., Microsporum spp., дрожжей: Candida spp. и в особенности против Malassezia spp. Кетоконазол подавляет рост этих грибов в концентрациях, в 25-30 раз меньших, чем остальные противогрибковые препараты, применяемые в терапии СД, и в несколько раз меньших, чем любые системные антимикотики. Он обладает высокой аффинностью (сродством) к кератинизированным тканям, способностью к крепкому связыванию с волосом и кератиноцитами. При нанесении местных форм кетоконазола на кожу эффрективные концен- 
трации сохраняются внутри и на поверхности эпидермиса в течение 72 ч. после отмены препарата. Случаев устойчивости грибов к кетоконазолу в настоящее время не зарегистрировано [13, 14]. При поражении волосистой части головы кетоконазол чаще используется наружно в форме шампуня. Их обычно применяют несколько раз в неделю, с обязательной аппликацией пены на 3-5 мин. до смывания. В последнее время наряду с шампунями успешно используются и другие формы, удобные для нанесения на кожу волосистой части головы: пены и гели [15].

Первое сообщение о положительном эффекте кетоконазола при СД было опубликовано в 1982 г. В 4 ранних крупных рандомизированных двойных слепых испытаниях, в которых сравнивали эффрективность шампуня с 2\% кетоконазола и шампуня, содержащего 2,5\% селена сульфида, было показано, что кетоконазол был эффрективнее селена сульфида и что к концу 4-й недели после окончания лечения это различие становилось статистически значимым. Шампунь с кетоконазолом уже через 3 нед. лечения значительно уменьшал жирность волос - одно из наиболее неприятных для больных проявлений перхоти и СД. В то же время было отмечено, что длительное применение шампуня, содержавшего 2,5\% селена сульфида, реактивно усиливает секрецию кожного сала. Это приводило к увеличению колонизации кожи дрожжевыми грибами, для которых сало являлось идеальной питательной средой [16, 17].

Зарубежными дерматологами было проведено сравнительное исследование двух групп больных с распространенным СД. Больные одной группы лечились шампунем, содержавшим $2 \%$ кетоконазола, больные другой группы - лосьоном, содержавшим 0,5\% бетаметазона дипропионата. Больных обследовали клинически и микологически в течение 4 мес. лечения и затем в течение 1 мес. после прекращения лечения. Через месяц после начала лечения положительный эфрфект был достигнут у 90\% больных, получавших кетоконазол, и у 73\% больных, получавших бетаметазон. В группе, применявшей шампунь с кетоконазолом, шелушение и зуд уменьшились в гораздо большей степени, чем в группе, использовавшей лосьон с бетаметазоном. Через 4 мес. лечения эритема и зуд статистически значимо уменьшились в группе, применявшей шампунь с кетоконазолом $(p<0,02)$, а уменьшение выраженности шелушения приблизилось к границе статистической значимости $(p=0,05)$. В конце первого месяца и в конце всего курса лечения в группе больных, применявших шампунь с кетоконазолом, было отмечено статистически значимое $(p<0,05)$ снижение количества дрожжевых клеток. Спустя один месяц после прекращения лечения частота рецидивов была более высокой в группе больных, использовавших лосьон с бетаметазоном, чем среди больных, которые пользовались шампунем с кетоко- назолом, что свидетельствует о более стойком положительном эффректе кетоконазола. У некоторых больных с сильной перхотью и тяжелым СД развивалась зависимость от местных стероидных препаратов, после прекращения нанесения которых наступало резкое обострение болезни [18].

Группой немецких ученых было проведено многоцентровое двойное слепое плацебо-контролируемое исследование эффрективности шампуня $2 \%$ кетоконазола у 575 пациентов с умеренной и тяжелой фрормами СД волосистой части головы и перхоти. Применение 2\% кетоконазола в виде шампуня 2 раза в неделю в течение 2-4 нед. показало выраженный терапевтический эфрфект у 88\% пациентов. Из тех, которые ответили на терапию, 312 были включены в последующий профилактический этап продолжительностью 6 мес. Эти пациенты были разделены на три равные группы: пациенты 1-й группы использовали активный препарат (шампунь, содержащий $2 \%$ кетоконазола) один раз в неделю, пациенты 2-й группы использовали шампунь, содержащий $2 \%$ кетоконазола, чередуя с плацебо (шампунь без кетоконазола), один раз в неделю, пациенты 3-й группы - только плацебо один раз в неделю. В конце срока наблюдения рецидив отметили 47\% пациентов из группы плацебо, 31\% из 2-й группы (активной препарат и плацебо) и только 19\% больных в группе активного лечения. Препарат хорошо переносился во всех группах. На основании полученных результатов авторы пришли к выводу, что шампунь $2 \%$ кетоконазол является весьма эффрективным не только в терапии СД, но и для предотвращения рецидивов заболевания при профилактическом использовании один раз в неделю [19].

Группой канадских дерматологов было выполнено рандомизированное двойное слепое плацебо-контролируемое исследование шампуня, содержащего $2 \%$ кетоконазола, в сравнении с шампунем, содержащим 2,5\% селена сульфида, в лечении 246 пациентов с умеренной и тяжелой формами перхоти и СД. Результаты исследования показали, что оба лечебных шампуня - с $2 \%$ кетоконазола и 2,5\% селена сульфида эффрективные лекарственные средства и статистически превосходят плацебо в устранении симптомов перхоти СД. Шампунь с кетоконазолом давал более быстрый терапевтический эффрект, чем шампунь с селена сульфидом ( $p=0,0026)$. Оба лечебных шампуня были значительно эффективнее, чем плацебо, в скорости и активности снижения раздражения и зуда кожи. Хотя в целом не было никаких статистически значимых различий между двумя лечебными шампунями, все девять негативных симптомов, о которых сообщалось в течение лечения, определялись у пациентов, получавших селена сульфид. Наиболее часто пациенты жаловались на зуд, жжение кожи, окрашивание и обесцвечивание волос. Проведенное анкетирование среди пациентов показало, что 84,6\% паци- 
ентов, получавших лечение кетоконазолом, отметили хороший, очень хороший или прекрасный результат лечения. В группе применявших селена сульфид такой результат отметили лишь 73,6\%, а в группе плацебо - 41,6\% [20].

В клиническом исследовании, проведенном Ю.В. Сергеевым и А.Ю. Сергеевым, оценивалась эффективность шампуня $2 \%$ кетоконазола (Низорал) у 35 больных с перхотью и 21 больного с СД. Лечение проводилось 2 раза в неделю в течение 2-4 нед. При выраженных явлениях СД, наличии инфильтрации, покраснения перед назначением шампуня применяли местное втирание кортикостероидных кремов и лосьонов в течение 2-3 дней для быстрого снятия острых явлений. Эффрективность лечения оценивали через 4 недели. Наилучшие результаты были получены у больных с перхотью: клиническое выздоровление у $85,7 \%$ больных. При СД клиническое выздоровление отмечено у $71,4 \%$, значительное улучшение у $14,2 \%$, улучшение - у 14,3\% больных. Все больные переносили лечение хорошо, побочных эфрфектов не отмечалось. После окончания курса лечения пациентам рекомендовали профилактическое применение шампуня Низорал 1 раз в неделю [21].

Исследование, проведенное американскими дерматологами, показало эффрективность и безопасность кетоконазола $2 \%$ пена для лечения СД кожи головы и лица. 1062 пациента в возрасте от 12 лет и старше с различными с формами (от легкой до тяжелой) СД были рандомизированы на 4 группы: 1-я - лечение пеной кетоконазола ( $n=427)$, 2-я - пеной-плацебо $(n=420)$, 3-я - кремом кетоконазола $(n=210), 4$-я кремом-плацебо ( $n=105)$, используемыми дважды в день в течение 4 нед. Результаты оценивались по баллам статистической глобальной исследовательской оценки (SGA), определяющей активность выраженности клинической симптоматики от 0 (нет симптома) до 3 (максимальная выраженность симптома).

Эфрфект от лечения определялся количеством пациентов, имеющих в конце 4-й недели терапии баллы 0-1. Значительно бо́льший процент пациентов, достигших успешных результатов лечения, использовали кетоконазол пену, чем плацебо пену (56 и 42\% соответственно; ( $p<0,0001)$, использование кетоконазола пены было эквивалентно крему кетоконазола. Кетоконазол пена хорошо переносилась пациентами, незначительные побочные эфффекты наблюдались у $14 \%$ (у 59 из 427) [22].

Изучение эфрфективности и переносимости кетоконазола 2\% в фрорме геля по сравнению с плацебо-гелем у 900 пациентов с умеренной и тяжелой формами СД волосистой части головы показало, что доля эффективно излеченных пациентов была значительно выше в группе, использующей гель 1 раз в день, по сравнению с группой, получавшей плацебо $(p<0,001)$. Гель почти невидим после нанесения в отличие от крема кетоконазола и может являться препаратом выбора для пациентов, ведущих активную общественную жизнь, что значительно повышает приверженность лечению. В этом же исследовании было проведено сравнение эффективности геля кетоконазола и комбинации гель кетоконазол + дезонид гель. Отмечено, что эффрективность в отдельности кетоконазола была сравнима с таковой в комбинации гель кетоконазол + дезонид гель в течение 2 нед. после окончания лечения. Авторы пришли к заключению, что применение $2 \%$ геля кетоконазола 1 раз в день является эффрективным средством для лечения СД и реальной альтернативой $2 \%$ крема кетоконазола [23].

Проведено 64 международных клинических исследования оригинального шампуня Низорал с кетоконазолом 1 и 2\% при участии 8189 пациентов с перхотью и/или СД - данные включены в мета-анализ, осуществленный P. De Doncker и соавт. Большинство (59\%) исследований были двойными слепыми (из них 58\% - плацебо-контролируемыми, остальные - с активным контролем), 31\% - открытыми, остальные с различным дизайном. Положительный эффрект от применения 2 раза в неделю шампуня Низорал с 2\% кетоконазолом был отмечен через 2 нед. у 78\% пациентов с СД и через 4 нед. - у 89\%. У пациентов с выраженной перхотью шампунь кетоконазола $2 \%$ был статистически значимо эффрективнее шампуней, содержащих 1\% цинка пиритиона и 1\% кетоконазола. Частота рецидивов после терапии шампунем кетоконазола $2 \%$ отмечалась (в среднем) у $33 \%$ пациентов с СД (оценка в течение 2-26 нед.). В то же время возобновление клинической симптоматики после применения селена сульфида отмечалось у 76\% больных в период от 3 до 11 нед., пиритиона цинка - у 51\% больных, после использования $0,1 \%$ лосьона с мометазоном - у 87\% (оба 12 нед.) [24].

W. Apasrawirote, M. Udompataikul в 2011г. провели мета-анализ, в ходе которого были рассмотрены 1095 исследований, изучавших эффрективность наружных антимикотических средств в лечении СД: кетоконазола, бифоназола и циклопирокса. Мета-анализ в данном исследовании показал, что среди сравниваемых препаратов сильные показатели эффективности продемонстрировал кетоконазол, умеренные - циклопирокс и слабые - бифоназол [25].

Таким образом, шампунь с $2 \%$ кетоконазола (Низорал) обладает высокой антимикотической, противовоспалительной и противосеборейной активностью, эфффективно подавляет как рост грибов, так и симптомы воспаления и зуда. Общий клинический ответ на местное лечение шампунем, содержащим 2\% кетоконазола, варьировал, по данным различных исследований, от 42 до 91\% (среднее значение 88\%). Он может использоваться как для лечения обострений перхоти и СД, так и для предотвращения рецидивов. Шампунь 
с 2\% кетоконазола обладает большей длительностью действия по сравнению с другими шампунями. Устойчивости Malassezia к кетоконазолу не зарегистрировано. Шампунь обладает хорошей переносимостью, отвечает требованиям безопасности при использова- нии в домашних условиях, сохраняя свои свойства в присутствии поверхностно-активных веществ. Низорал шампунь удобен в использовании на волосистую часть головы, привлекателен с косметической точки зрения, обладает высокой комплаентностью. І

\section{Литература}

1. Plewig G, Janssen T. Seborrheic dermatitis. In: Wolff $K$, Goldsmith LA, Katz SI, et al., editors. Fitzpatrick's Dermatology in General Medicine. 7th ed. New York: McGraw-Hill; 2008.

2. Cupta AK, Bluhm R. Seborrheic dermatitis J Eur Acad Dermatol Venereol 2004; 18113-26.26; quiz, 19-20.20.

3. Mahe A, Simon F, Coulibaly S, et al. Predictive value of seborrheic dermatitis and other common dermatoses for HIV infection in Bamako, Mali. J Am Acad Dermatol 1996; 34(6): 1084—1086.

4. Binder RL, Jonelis FJ. Seborrheic dermatitis in neuroleptic-induced parkinsonism. Arch Dermatol 1983; 119(6): 473-475.

5. Araviyskaya Ye.R., Sokolovskiy Ye.V. Textbook of Dermatocosmetology.SBb; 2008. [Руководство по дерматокосметологии под редакцией Е.Р. Аравийской и Е.В. Соколовского. СПб., 2008.]

6. Gajigoroeva A.G.Dandruff and seborrheic dermatitis. Dermatology 2007; 1: 9—14. [Гаджигороева А.Г. Перхоть и себорейный дерматит. Дерматология 1: 2007; 9-14. Приложение к журн.Consilium medicum.]

7. Ileshina T.B. Seborrhoeic dermatitis Rus med j.2004 5: 324-327. [Илешина Т.В. Себорейный дерматит. Рос мед журн, 2004 г., № 5, с. 324-327.]

8. Faergemann J, Bergbrandt I, Dohse M, Scott A, Westgate G. Seborrheic dermatitis and Pityrosporum (Malassezia) folliculitis: Characterization of inflammatory cells and mediators in the skin by immunohistochemistry. Br J Dermatol. 2001; 144: 549—-556

9. Tajima M, Sugita T, Nishikawa A, Tsuboi R. Molecular analysis of Malassezia microflora in seborrheic dermatitis patients: Comparison with other diseases and healthy subjects. J Invest Dermatol. 2008; 128(2): 345-351.

10. Kerr K, Darcy T, Henry J, Mizoguchi H, Schwartz J, Morrall $\mathrm{S}$, et al. A description of epidermal changes associated with symptomatic resolution of dandruff: Biomarkers of scalp health. Intl J Derm 2011; 50: 102—113.
11. Harding C, Moore A, Rogers J, Meldrum H, Scott A, McGlone F. Dandruff: a condition characterized by decreased levels of intercellular lipids in scalp stratum corneum and impaired barrier function. Arch Dermatol Res. 2002; 294: 221—230.

12. James R. Schwart 21 , Andrew G. Messenger, Antonella Tosti, Gail Todd and all. A comprehensive pathophysiology of dandruff and seborrheic dermatitis - towards a more precise definition of scalp health. Acta Derm Venereol 2013; 93: 131_137.

13. Thomas Berk, MD and Noah Scheinfeld, MD Seborrheic Dermatitis Pharmacy and therapeutics, 2010 June; 35(6): 348-352.

14 Cupta AK, Nicol K, Batra R. Role of antifungal agents in the treatment of seborrheic dermatitis. Am J Clin Dermatol. 2004: 5(6): 417-422.

15 Shin $\mathrm{H}$, Kwon OS, Won $\mathrm{CH}$, et al. Clinical efficacies of topical agents for the treatment of seborrheic dermatitis of the scalp: A comparative study. J Dermatol. 2009; 36(3): 131-137.

16 Pierard GE. Pierard-Franchimont C, Ben Mosbah T. Les pityrosporses: pityriasis versicolor, folliculite pityrosporique. dermatite scborrheique et etat pellicularie. /tev Med Liege 1989: XLW7): 267-271.

17 Tanew A. A randomised study with ketoconazole shamp00 $2 \%$ or Selsun R (selenium sulphide $2.5 \%$ ) in the treatment of seborrhoeic dermatitis and/or dandruff. Beerse, Belgium: Janssen Pharmaceutica, 1987. (Data on file).

18 Ortonne J-P, Lacour J-P. Vitetta A. 2\% ketoconazole vs $0.05 \%$ betamethasone in the treatment of seborrhoeic dermatitis. Beerse, Belgium: Janssen Pharmaceutica. (Data on file.)

19 Peter RU, Richarz-Barthauer U. Department of Dermatology, University of Munich, Germany. Successful treatment and prophylaxis of scalp seborrhoeic dermatitis and dandruff with $2 \%$ ketoconazole shampoo: results of a multicentre, double-blind, placebo-controlled trial. Br J Dermatol. 1995 Mar; 132(3): 441—5.
20 William Danby, MD, FRcpC, a W. Stuart Maddin, MD, FRCPC, Lynette J. Margesson, MD, and Donald Rosenthal, MD, FRCPC Kingston and Hamilton, Ontario, and Vancouver, British Columbia, Canada. A randomized, double-blind, placebo-controlled trial of ketoconazole 20/0 shampoo versus selenium sulfide $2.5 \%$ shampoo in the treatment of moderate to severe dandruff. Journal of the American Academy of Dermatology December 1993.

21 Sergeev Yu.V., Sergeev A.Yu. Shampoo Nizoral: the modern approach to Malassezia treatment — skin infections. Vestnik dermatologii i venerologii.1997; 3: 60—62. [Сергеев Ю.В., Сергеев А.Ю. Шампунь Низорал: современный подход к лечению Malassezia - инфекции кожи. Вест дерматол и венерол 1997; 3: 60-62.]

22 Elewski BE, Abramovits W, Kempers S, Schlessinger J, Rosen T, Gupta AK, Abraham S, Rowell R. University of Alabama at Birmingham, Birmingham, AL 35294. USA. A novel foam formulation of ketoconazole $2 \%$ for the treatment of seborrheic dermatitis on multiple body regions. J Drugs Dermatol 2007 Oct; 6(10): 1001.

23 Swinyer LJ, Decroix J, Langner A, Quiring JN, Blockhuys S. Dermatology Research Center, Salt Lake City, Utah 84124 , USA. Ketoconazole gel $2 \%$ in the treatment of moderate to severe seborrheic dermatitis. Cutis 2007 Jun; 79(6): 475-82.

24 De Doncker et al. «Decade of Clinical experience with Ketoconazole Shampo0", 59th Annual meeting of the American Academy of Dermatology, 2001.

25 Apasrawirote W, Udompataikul M, Rattanamongkolgul S. Skin Center, Faculty of Medicine, Srinakharinwirot University Bangkok, Thailand. Topical antifungal agents for seborrheic dermatitis: systematic review and meta-analysis. J Med Assoc Thai. 2011 Jun; $94(6): 756-60$.

об авторах:

Т.А. Белоусова — к.м.н., доцент кафедры кожных и венерических болезней лечебного факультета ПМГМУ им. И.М. Сеченова Минздрава России, Москва

М.В. Горячкина - к.м.н., старший научный сотрудник лаборатории по изучению репаративных процессов в коже НОКЦ «Иммунозависимые дерматозы» ПМГМУ им. И.М. Сеченова Минздрава России, Москва

Д.Г. Катранова — клинический ординатор кафедры кожных и венерических болезней лечебного факультета ПМГМУ им. И.М. Сеченова Минздрава России, Москва 